Abstract PTU-017 Table 1 Outcome measures

\begin{tabular}{|c|c|c|c|c|c|c|}
\hline Authors & Study & Procedure completed & $\begin{array}{l}\text { Intra-operative } \\
\text { complications }\end{array}$ & $\begin{array}{l}\text { Procedure duration } \\
\text { (min(range)) }\end{array}$ & Specimen size (cm (range)) & Survival \\
\hline \multirow[t]{2}{*}{ Schurr et al. } & A\&S & $20 / 20(100 \%)$ & $5 / 10(50 \%) \& 0 / 10(0 \%)$ & - & Over $3 \mathrm{~cm}^{*}$ & \\
\hline & $A$ & $20 / 20(100 \%)$ & $3 / 10(30 \%)$ \& $0 / 10(0 \%)$ & - & - & \\
\hline Rajan et al. & $S$ & $8 / 8(100 \%)$ & $4 / 8(50 \%)$ & 30.2 & $3.6(1.5-5.2)$ & $8 / 8(100 \%)$ \\
\hline Raju et al. & $S$ & $19 / 20(95 \%)$ & $0 / 19(0 \%)$ & $50(24.5-67)$ & $1.7(1-2.5)$ & $19 / 20(95 \%)$ \\
\hline Von Renteln et al. & $A$ & $9 / 20(45 \%) \& 8 / 8(100 \%)$ & $6 / 9(67 \%) \& 2 / 8(25 \%)$ & $14.8(7-36) \& 31.5(21-42)$ & $3.3(2.4-5.5)$ & \\
\hline Rieder et al. & A & $2 / 2(100 \%)$ & $0 / 2(0 \%)$ & $33+/-4$ & $2.2+/-0.1$ & \\
\hline Von Renteln et al. & $S$ & $8 / 8(88 \%)$ & $2 / 8(25 \%)$ & $3(2-12)$ & $7.6 \mathrm{~cm}^{2}\left(5.4-11 \mathrm{~cm}^{2}\right)$ & $7 / 8(88 \%)$ \\
\hline Kennedy et al. & A\&S & $3 / 3(100 \%) \& 4 / 4(100 \%)$ & $0 / 3(0 \%) \& 0 / 4(0 \%)$ & $233(201-245)^{* *}$ & $2.5(2-3) \& 3.5(3.5-4)$ & $4 / 4(100 \%)$ \\
\hline Total & & $101 / 113(89 \%)$ & $22 / 101(22 \%)$ & & & $48 / 50(96 \%)$ \\
\hline
\end{tabular}

Abbreviations: $A$ = acute study, $S=$ survival study; ${ }^{*}$ Reported for 5 animals only, ${ }^{*}$ Reported for survival group only

complications. The need for an alternative, less invasive treatment option for this patient cohort is becoming increasingly clear.

Methods Systematic literature searches identified articles describing EFTR in the colon of adult pigs, published 1990-2012. Complication rates, anastomotic bursting pressures, procedure duration, specimen size and quality, and post-mortem findings were analysed. Results Four EFTR techniques using endoscopic stapling devices, T-tags, compression closure or laparoscopic assistance for defect closure before or after specimen resection were reported. 113 procedures were performed in 99 porcine models (Table 1), with an overall success rate of $89 \%$ and a $4 \%$ mortality. The intraoperative complication rate was $22 \%(0 \%>67 \%)$. Post-resection closure methods (as opposed to simultaneous resection and closure) more commonly resulted in failure to close the defect $(5 \%>55 \%)$ and a high incidence of abnormal findings at post-mortem examination (84\%). Significant heterogeneity was observed in procedure duration (average $3 \mathrm{~min}$ to $233 \mathrm{~min}$ ) and size of the excised specimen (average $1.7 \mathrm{~cm}$ to $3.6 \mathrm{~cm}$ ). Anastomotic bursting pressures and specimen quality were poorly documented.

Conclusion The technique of EFTR is in development, with experience currently limited to preclinical studies. The inability to close the resection defect reliably is the primary obstacle to further progress. This review highlights the challenges that need to be addressed in future preclinical studies.

Disclosure of Interest None Declared

\section{PTU-018 CAN CHROMOENDOSCOPY HELP IN COELIAC DISEASE AS PART OF A DUODENAL BIOPSY STRATEGY?}

doi:10.1136/gutjnl-2013-304907.111

1."A J Johnston, 'M Kurien, 'K E Evans, 'A Averginos, 'D S Sanders. 'Department of Gastroenterology, Royal Hallamshire Hospital, Sheffield, UK

Introduction Chromoendoscopy is increasingly being used to detect, localise and characterise mucosal abnormalities, however its role in coeliac disease remains to be established. Endoscopic markers of coeliac disease (reduction of folds, scalloping, mosaic pattern, visible blood vessels and nodularity of the duodenal folds) are often difficult to recognise, therefore many centres take routine duodenal biopsies or have a low threshold for biopsy, ensuring high detection rates. This study evaluates if dye spray can improve identification of endoscopic markers of coeliac disease, potentially leading to a biopsy avoidance strategy.

Methods Patients undergoing clinically indicated oesophogastroduodenoscopy (OGD) were prospectively recruited from a single endoscopy list between January 2011 and November 2012. Patients were divided into two groups: patients with no previous history of coeliac disease (Group 1, $\mathrm{n}=201$ ) and patients with established coeliac disease (Group 2, $n=24$ ). Eight experienced endoscopists undertook all procedures, with endoscopic findings reported both before and after the use of indigo carmine dye spray. Endoscopic findings were compared using a McNemar test, with $\mathrm{p}$ values $<0.05$ considered significant. In addition, endoscopic findings were compared to histological findings to determine sensitivity, specificity, positive predictive values (PPV) and negative predictive values (NPV) for differing endoscopic techniques.

Results Of the 225 patients recruited, 97 (43\%) had positive serology (either endomysial or tissue transglutaminase antibodies). In Group 1, 61(30\%) were newly diagnosed coeliac patients with endoscopic markers identified in 44\% (27/61). Dye spray use within the duodenum identified a further 5 patients (32/61, 52\%), however this improvement in diagnostic yield was not statistically significant $(\mathrm{P}=0.63)$. Sensitivity, specificity, positive and negative predictive values for standard endoscopy to detect coeliac disease were $44 \%, 99 \%$, $93 \%, 80 \%$ respectively compared to $52 \%, 99 \%, 94 \%, 83 \%$ for chromoendoscopy. In Group 2, 12 patients had persisting Marsh 3 changes at biopsy, however endoscopic markers were identified in only $5(21 \%)$ with dye only increasing yield by a further one patient $(6 / 24,25 \%)$.

Conclusion Dye spray is easy to use and inexpensive $(<£ 1 /$ endoscopy), however in our study derived no additional benefit to conventional endoscopy for diagnosing patients with coeliac disease. Given the low sensitivity of endoscopic markers, we advocate duodenal biopsies in all patients where there is a high clinical suspicion of coeliac disease, irrespective of the endoscopic mucosal findings.

Disclosure of Interest None Declared

\section{PTU-019 A COMPARISON OF TWO COLONOSCOPE WITHDRAWAL TECHNIQUES: INTERIM ANALYSIS OF A RANDOMISED CROSS OVER STUDY}

doi:10.1136/gutjnl-2013-304907.112

1,*A J Ball, 'S S Johal, 'S A Riley. 'Gastroenterology, Sheffield Teaching Hospitals, Sheffield, UK

Introduction Many endoscopists withdraw the colonoscope with the patient in a single position (left lateral or supine), while others advocate position change. A previous study in a small group of patients suggested position change is beneficial in the transverse and left colon. We have compared colonoscope withdrawal in the supine position with position change.

Methods A randomised cross-over study compared colonoscope withdrawal in the supine position with position change (caecum to 
hepatic flexure in the left lateral position, transverse colon in the supine position and the hepatic flexure and descending colon in the right lateral position). Colonic segments were precisely defined using biopsy sites as markers, aided by a Scopeguide imager. Segments were cleansed and examined for at least 2 minutes during which air was insufflated to distend the colon. After each segment was examined the colonoscope was reinserted and the same segment was re-examined in the alternative position. Luminal distension was rated on a validated 5 point scale, ranging from $1=$ completely collapsed to $5=$ maximal distension. Ordinal and categorical data were compared with the Mann Whitney $U$ test and Fisher's exact test respectively.

Results This is an interim analysis of 65 patients (mean age 62, 38 male). 30 patients were initially examined in the supine position and 35 patients with position change. Distension scores were higher in the right colon when examined in the left lateral position (mean $=3.9$ vs. $3.5 p=<0.001$ ), and in the left colon when examined in the right lateral position (4.4 vs. 3.6, $p=<0.001$ ) (see table 1 ). The proportion of patients with scores of 4-5 (adequate) were higher in the right colon when examined in the left lateral position (42/65 vs. $27 / 65, p=0.014)$ and in the left colon when examined in the right lateral position $(59 / 65 \mathrm{vs} .34 / 65, \mathrm{p}=<0.001)$. There was no significant carry-over effect in any of the examined segments.

Abstract PTU-019 Table 1 Distribution of distension scores with each colonoscope withdrawal strategy

\begin{tabular}{llllll}
\hline & \multicolumn{5}{l}{ Distension score } \\
\cline { 2 - 6 } Withdrawal position & $\mathbf{1}$ & $\mathbf{2}$ & $\mathbf{3}$ & $\mathbf{4}$ & $\mathbf{5}$ \\
\hline Right colon & 0 & 5 & 33 & 19 & 8 \\
Supine & 0 & 0 & 22 & 26 & 16 \\
Left Lateral & & & & & \\
Descending colon & 0 & 2 & 29 & 29 & 5 \\
Supine & 0 & 0 & 6 & 26 & 33 \\
Right lateral &
\end{tabular}

Conclusion Position change improves suboptimal distension of the right and left colon. Further analysis of this study will clarify whether position change also improves polyp detection.

Disclosure of Interest None Declared

\section{REFERENCES}

East JE et al. Position changes improve visibility during colonoscope withdrawal: a randomised, blinded, crossover trial. Gastrointest Endosc. Feb 2007; 65(2):263-269.

East JE et al. Dynamic patient position changes during colonoscope withdrawal increase adenoma detection: a randomised, crossover trial. Gastrointest Endosc. Mar 2011; 73(3):456-463.

\section{PTU-020 PRE-ENDOSCOPIC INTRAVENOUS PROTON PUMP INHIBITION AND THE OUTCOMES OF ACUTE UPPER GASTROINTESTINAL BLEEDING}

doi:10.1136/gutjnl-2013-304907.113

1.2. A S Taha, ${ }^{2} \mathrm{E}$ Saffouri, ${ }^{1} \mathrm{C}$ McCloskey, ${ }^{1} \mathrm{~T}$ Carigen, ${ }^{3} \mathrm{~W} \mathrm{~J}$ Angerson. 'Medicine, University Hospital Crosshouse, Kilmarnock; '2Medicine; '3 Surgery, Unversity of Glasgow, Glasgow, UK
Introduction Proton pump inhibitors (PPIs), when given following endoscopy for acute upper gastrointestinal bleeding (UGIB), can reduce the need for blood transfusion and surgery; little is known about their benefit when used in the period before endoscopy.

We therefore aimed to investigate the outcomes of UGIB in patients given intravenous PPIs before their endoscopy.

Methods A total of 404 patients with UGIB were included; 202 received intravenous omeprazole for a median of 1 day (IOR 0.25-2) before endoscopy and 202 did not, this treatment being at their physician's discretion. Omeprazole was given either in bolus doses of $40-\mathrm{mg}$ bid ( $\mathrm{n}=103 ; 51 \%$ ), or as an infusion of $8-\mathrm{mg} /$ hour after a loading dose of $80-\mathrm{mg}(\mathrm{n}=99 ; 49 \%)$. After endoscopy, omeprazole was continued intravenously or orally in patients found to have ulcers/erosions in their oesophagus, stomach, or duodenum. Patients' clinical details were noted including their Charlson comorbidity and Blatchford risk scores. Three major outcomes were measured: need for blood transfusion; hospital stay $>6$ days; and death within 30 days. The Mann-Whitney test, Chi-squared test and logistic regression were used as appropriate

Results The two groups were comparable with respect to their gender, smoking, alcohol intake, and use of NSAIDs, aspirin, antithrombotic and other drugs. The treated group was older and had higher Blatchford and Charlson scores. However, when these factors were adjusted for, as shown in Table-1, below, no significant differences were noted between patients who received pre-endoscopic PPI and those who did not in terms of need for blood transfusion, length of hospital stay, or 30-day mortality.

Conclusion The administration of intravenous PPI before endoscopy did not affect the outcomes of acute upper gastrointestinal bleeding in this retrospective study. This is relevant to the appropriate management of this common condition.

Disclosure of Interest A. Taha Consultant for: Horizon Pharma USA; Vifor Pharma UK, E. Saffouri: None Declared, C. McCloskey: None Declared, T. Carigen: None Declared, W. Angerson: None Declared

\section{PTU-021 3D RECONSTRUCTION IN CAPSULE ENDOSCOPY; A FEASIBILITY STUDY}

doi:10.1136/gutjnl-2013-304907.114

1."A Koulaouzidis, ${ }^{2} \mathrm{~A}$ Karargyris, ${ }^{3} \mathrm{E}$ Rondonotti, ${ }^{1} \mathrm{~J}$ N Plevris. ${ }^{1}$ Centre for Liver \& Digestive Disorders, Royal Infirmary of Edinburgh, Edinburgh, UK; ${ }^{2}$ National Institutes of Health, National Library of Medicine, Bethesda, United States; ${ }^{3}$ Gastroenterology Unit, Ospedale Valduce, Como, Italy

Introduction Three-dimensional (3D) imaging in small-bowel capsule endoscopy (SBCE) is not currently feasible due to hardware limitations. However, there has been increasing use of software algorithms to enable 3D reconstruction in this setting. The aim of this study was to explore a) whether innovative software offers accurate $3 \mathrm{D}$ reconstruction of monocular images and b) if its application leads to enhanced lesion visualisation in SBCE.

Methods Feasibility study; first, a phantom was designed to test the accuracy of $3 \mathrm{D}$ reconstruction by comparing images of red, yellow and white phantom models to their $2 \mathrm{D}$ counterparts. Thereafter, a total of 192 SBCE images (84 PillCam $^{\circledR} / 108$ MiroCam $^{\circledR}$;

Abstract PTU-020 Table 1 Odds ratios (95\% Cl) for outcomes of UGIB, with vs. without pre-endoscopic PPI use, before and after adjustment for other factors in a logistic regression model

\begin{tabular}{lllll}
\hline Outcome & Un-adjusted & Adjusted for Age & $\begin{array}{l}\text { Adjusted for Age \& Blatchford } \\
\text { Score }\end{array}$ & $\begin{array}{l}\text { Adjusted for Age, Blatchford \& } \\
\text { Charlson Scores }\end{array}$ \\
\hline Transfusion & $2.11(1.41-3.16) ; P<0.001$ & $1.87(1.24-2.84) ; P=0.003$ & $1.16(0.69-1.97) ; P=0.57$ & $1.08(0.63-1.84) ; P=0.78$ \\
Length of Stay $>6$ Days & $1.48(1.00-2.19) ; P=0.052$ & $1.24(0.81-1.89) ; P=0.33$ & $0.98(0.63-1.53) ; P=0.94$ & $0.99(0.63-1.65) ; P=0.97$ \\
30-Day Mortality & $1.80(0.74-4.38) ; P=0.20$ & $1.57(0.64-3.87) ; P=0.33$ & $1.16(0.46-2.96) ; P=0.75$ & $1.34(0.50-3.59) ; P=0.56$ \\
\hline
\end{tabular}

